\title{
PHOTOPOLYMER AND LATEX LIFT \\ DEMONSTRATIONS: STRATEGY TO \\ PROBLEMATIZE SPAGHETTI-LIKE REPRESENTATION IN POLYMER CHEMISTRY
}

\author{
Alceu Junior Paz da Silva \\ Fluminense Federal University, Volta Redonda, Brazil \\ Leopoldo José Alexandre \\ Albert Einstein High School, Pinheiral, Brazil
}

Agnaldo Arroio

University of São Paulo, São Paulo, Brazil

\begin{abstract}
Despite several technological processes and products found in everyday life involve polymers, it has been neglected in Chemistry Education. In this paper, the using of spaghetti-like representations in polymer teaching was explored. For this, a short course for undergraduate chemistry students was developed and constituted by two didactic sequences. In each of them one demonstrative experiment (latex lift and photopolymerization) was used to promote practices of externalization of visual models. The analysis of the students' drawings and written texts showed demonstrations of problematized concepts relevant to polymer teaching, whereas the effectiveness of spaghetti-like representations' employment requires further research. The initiative was well-founded and satisfactory within an initial exploratory perspective and implementation of this strategy in regular disciplines can promote the increase of students' interest in polymer chemistry, an essential knowledge area for developing countries that need to build their own technologies and innovation.
\end{abstract}

Keywords: visualization in chemistry, spaghetti representation, teaching of polymer.

\section{Introduction}

Nowadays, several technological processes and products found in everyday life involve Polymers Chemistry, from plastics, rubbers, fibers, coating, adhesives, and biomaterials to gene therapy and smartphones. If on the one hand these advanced or everyday technologies have promoted comfort and quality of life, on the other hand, says Douglas (2008, p. 583) "the societal impacts have increased, bringing up issues such as recycling due to necessity of renewable sources and human safety because of additives and contamination by residual monomers".

Despite their relevance, polymers have been neglected in Chemistry Education once some concepts are addressed in inorganic or organic chemistry courses and others, such as conditions to produce and control the chain lengths and aspects of chemical thermodynamics, commonly are not taught into undergraduate degrees in Chemistry, according to Ford (2017). In Brazil, Polymers Chemistry is usually included in Chemistry, Chemical Engineering or Materials Engineering study programs while that normally it is not offered in teacher education program (Santos, Dias, \& Canevarolo, 2015).

In turn, the education of researchers and that of industrial employees has required a holistic thinking for articulating concepts of polymer chemistry, physics and engineering. According to North (2015), for instance, a "bridge of understanding" between chemical 
structure of polymer and macroscopic physical behavior can be propitiated by the molecular motion while that holistic thinking has been very important mainly for developing countries seeking to develop their own technologies and innovations.

In this context, initiatives in undergraduate's courses about polymer education were confirming the importance of those structure-property relationships as well as assuming hands-on activities or theoretical-descriptive ways like strategies of teaching. However, in order to establish these relations between the theoretical world (concepts and chemical structures) and everyday world (properties, products and experiments) a multimodal perspective must be taken into account, because both in teaching and learning of scientific knowledge's " [...] is necessary to juggle and combine in various canonical ways verbal discourse, mathematical expression, graphical-visual representation, and motor operations in the world (Lemke, 1998, p. 87)".

In one of these modes (visual-pictorial) was found the spaghetti-like representation, in its amorphous and crystalline forms, which can help to articulate chemical properties and concepts with polymeric physical behavior. Due to this mediating and pedagogical role and the fact that polymers are currently underrepresented in the undergraduate chemistry, this work started from the question: How can the use of spaghetti-like representations be explored to problematize basic concepts of polymer chemistry?

For this, a teaching strategy was elaborated and implemented with the objective of increasing students' interest for the learning of scientific concepts related to polymer phenomena as well as their technological applications.

\section{Visualization in Polymer Chemistry Mediated by Spaghetti-Like Representation}

The path taken by scientific work to explain and predict the macroscopic properties of materials and their transformations necessarily involves the creation of explanatory models. Like a theoretical model, the use of spaghetti-like representation is not recent. Usually, investigations into the morphology of materials have used the term "spaghetti" or "spaghetti-like" to representing polymer molecules' state of aggregation. But in Chemistry degrees, more specifically in General Chemistry courses, this representation is little explored, most probably, because it is not recognized and standardized by community of chemical scientists (IUPAC, 1997).

This fact does not reduce its importance in early chemistry teaching. When a return to the origin of life is thought, the first challenges of connecting the various simple and "small" molecules for the formation of a "giant" selective membrane, when compared to the size of them, can be imagined. From a long evolutionary journey, another process can be imagined as the complex combining ability of "small" amino acid molecules (like pieces of a puzzle) for producing new and "giant molecules" responsible for the most varied biochemical properties and functions, which are the proteins.

So, when a molecule is made up of a large number of atoms, it begins to acquire specific properties that exceed the original characteristics of its atoms and its functional groups, it being called the macromolecule. These characteristics are determined by intramolecular interactions (between segments of the macromolecule itself) and intermolecular (between different macromolecules) interactions. In its turn, polymers are substances composed by macromolecules in which other factors also contribute to differentiate their properties from proprieties of those small molecules (or monomers) from which they were formed. 
The necessity to create an explanatory model that represents those characteristics brings to light the fact that chemical thought (chemical philosophy) is distributed in three different levels. The chemical thought can be represented in a macro level characterized by tangible and visible macrophenomena, a submicro level constituted by atomic-molecular and kinetic models (abstract instances that are difficult to build) and a symbolic level in which is formed by symbols, equations, stoichiometry, and mathematics, according to Johnstone (1991; 1993).

For instance, in General Chemistry textbook of Atkins and Jones (2012), those representational levels can be found like: i) A surface of a tire is represented by a realistic photo (macro), polyisoprene chains with disulfide cross-linking are represented by atomic space filling model (submicro) and polyisoprene chains with cross-linking are represented by cylinders and yellow wires (intermediate or sub-level) as well as; ii) A small white ball inside the transparent test tube is represented by a realistic photo (macro), polyethylene chains are represented by atomic space filling model (submicro) and polyethylene chains are represented by orange lines in random distribution (intermediate or sub-level) (Atkins \& Jones, 2012).

Some implications for teaching are the facts that the rapid passage from one representational level to another (as is easily done by an experienced chemist) can mask the students' shortcomings both to understand and to autonomously transit between these levels and stagnating chemical learning, as well as a teaching approach that overemphasizes the simultaneity of levels, overloading students' thinking.

These assumptions are reasoned on Cognitive Load Theory (Sweller, 2010; Sweller, Ayres, \& Kalyuga, 2011) in which information store process (or learning) consists of schema construction and their storage on long-term memory (LTM). But this process is made by working memory (WM) which has low capacity and limited duration in the face of new information and unfamiliar problems. On the other hand, the schema already stored in the LTM can be borrowed to the WM, the fact that virtually increases its capacity and facilitates learning. This reveals that information (knowledge) must be organized (in the sense of diminishing cognitive load) in a way that does not overload working memory and facilitate the storage of schema.

On the way to this decrease in cognitive load, Mayer's studies (Mayer, 2009), about his Cognitive Theory of Multimedia Learning (CTML), pointed out that when presentation of the teaching materials uses words (written or spoken) and images (static [illustrations, graphs, photos, maps] or dynamic [animations, videos]) the learning is favored, because it is more deep from words and pictures than just from words. However, images and words are processed by different channels (visual/spatial channel and auditory/verbal channel) ranging from material presented, passing by sensory memory (registered separately by ears and eyes), and in WM the information is organized in a verbal model and a pictorial model which are integrated with each other and with the student's prior knowledge to be later stored in the LTM as constructed knowledge.

Therefore, a care must be taken not to overload the two channels once unlike spoken words that are processed by the verbal channel written words are initially processed by the visual channel along with the other visual elements of the instruction. As showed in Mayer (2014), during learning there are three cognitive processing which should be considered by instructional design in its task of don't overwhelm both channels of working memory. Whereas extraneous processing, produced by the teaching material presented, generates a cognitive demand that produces in WM inefficient knowledge for instructional purposes, 
essential processing refers to cognitive demand that builds a representation in WM of material presented, being caused by material' own complexity.

In turns, generative processing, caused by motivation to learn, involves the cognitive demand needed to making sense of the presented material, besides promoting the integration between verbal model, pictorial model and previous knowledge. These assumptions take the learning as an active and complex process in which the presented material with a coherent structure and with information able to provide a guide for building this structure can contribute to reduction of extraneous processing, management of essential processing and promotion of generative processing (Mayer, 2014).

In this way the mere addition of images to words does not ensure learning, if on the one hand the photo of a tire next to a polymeric molecular representation and within a verbal description (written words) cannot explore initially the auditory canal, on the other hand, the performance of student's learning depends also on his abilities and his knowledge previously stored in the LTM. These aspects put the didactic materials and the teacher's action before the task of mediating that verbal-pictorial-previous knowledge integration and, for this, the visualization processes assume a central role because they contribute to the development of mental models.

The visualization conceives the creation of an internal representation (like a mental model) from an external representation (pictures, diagrams, tables, graphics, etc.) which "can function as a bridge between scientific theory and the world-as-experienced (Gilbert, 2005 , p. 11)". In this process, the nature and temporal-spatial relationships between the entities that constitute external material are retained by learner and his internal representation can be used to predict the behavior of phenomena (Gilbert, 2008).

In addition, according Rapp (2005), mental models (internal representations) are abstractions, mutable and internally elaborated by interaction between stored knowledge (in LTM) and immediate experiences (external stimuli), but don't be an exact copy of these latter. They can be used "to generate hypotheses, solve problems, and transfer knowledge to new domains (Rapp, 2005, p. 45)", however their incomplete features can both facilitate and inhibit these processes.

Once a representation has been internalized a version of it can be externalized (expressed model). Recently, the complexity of visualization was advocated by Mnguni (2014, p. 07) as a divided cognitive process "into three non-linear overlapping stages", that is, Internalization, Conceptualization and Externalization of Visual Models while its domain involves both metavisualization and "the ability to acquire, monitor, integrate and extend learning from representations [both internal and external] (Gilbert, 2008, p. 05-06)".

In this context, metavisualization can be defined as the ability to: Understand the conventions of each type of representation (in its verbal, visual, symbolic, gestural, and concrete modes and its sub-modes in one, two or three dimensions in space [when possible]); translate a given mode into other modes or sub-modes in which they can be represented; elaborate a representation within any of the modes and sub-modes for a particular purpose; solve new problems using representations (as to draw a representational model already used in previous problems, either by providing suggestions for visual recall or by removing the irrelevant material from the perception), according to Gilbert (2008, p. 08).

Thus, visualization practices besides mobilizing different cognitive processes (CLT, CTML and others) and representational modes in their fundamentals need an appropriate way to present their didactic resources and learning tasks. Considerations about the influence of metacognition and motivation on cognitive processes (Mayer, 2014, p. 72) rein- 
force the idea of exploring visualization practices within a Teaching-Learning Sequence (TLS) once it interlaces epistemic and pedagogical dimensions considering teacher, learners, material world and knowledge to be developed besides its design being influenced by aspects such as motivation, students' conceptions, ways of reasoning, processes of developing knowledge, contradictions, analogies and modelling, in conception of Méheut (2005, p. 196 and 198).

In other words, the challenge is to use critically the visual tools (animations, simulations, statics or dynamics virtual 2D and 3D images) currently available to create a favorable learning environment in which visual representations do not have an end in themselves, because, according to Arroio (2012):

The very first moment when the students are exposed to these visual tools, the visual appeal is too strong. Draw the attention, so the motivation is assured. However, how to move beyond motivation, science lessons need to go beyond motivation, the engagement, they need to provide opportunities for students to build their models, their explanations, interpretations therefore, they must have the chance to express themselves, to communicate their own ideas about the scientific contents (Arroio, 2012, p. 113).

In the next section, a TLS inspired under these fundamentals and used to exploring spaghetti-like representations in teaching of polymer chemistry is described as well as the main functions of each artifact and action are highlighted.

\section{The Teaching-Learning Sequence Implemented}

The Teaching-Learning Sequence was divided in two small complementary sequences and constituted a short course of basic polymer concepts for undergraduate chemistry students. The course was planned to occur in six hours, divided into three days and was implemented in June 2017 in the Volta Redonda city, state of Rio de Janeiro, Brazil.

\section{Teaching-learning sequence of OLED}

Initially, students were invited to observe the behavior of a technological apparatus through exhibition of a video (Tim Schofield, 2013). After their observations was asked: How could the cell phone screen be folded with hands and continue working? What chemical concepts are involved in this phenomenon? At this point, this situation (initial challenge) has been set to produce motivation to learn.

A discussion was proposed for their prior knowledge circulating among students. From the finding insufficiency of mobilized scientific concepts, the students were invited to participate in a demonstration experiment that would help them to understand the chemical concepts involved in the initial phenomenon. One device in wood was mounted to observe the capacity of three different material samples, under and without heating, to support the weight of pliers. The name of the materials was not disclosed [garbage bag, cooking bag (more specifically, an oven cooking bag) and condom] and the students only used their hands to feel the samples.

The demonstrative experiment (latex lift) was inspired and adapted from Eidenberger, Gollner, Altendorfer and Eidenberger (2009, p. 35) in which the latex glove was 
replaced by condom and two other materials were added to produce different polymeric behaviors. First, the students had to predict what would happen to the material trapped in the device and the pliers when the heating (using a 500 W lamp) was started on the sample (garbage bag).
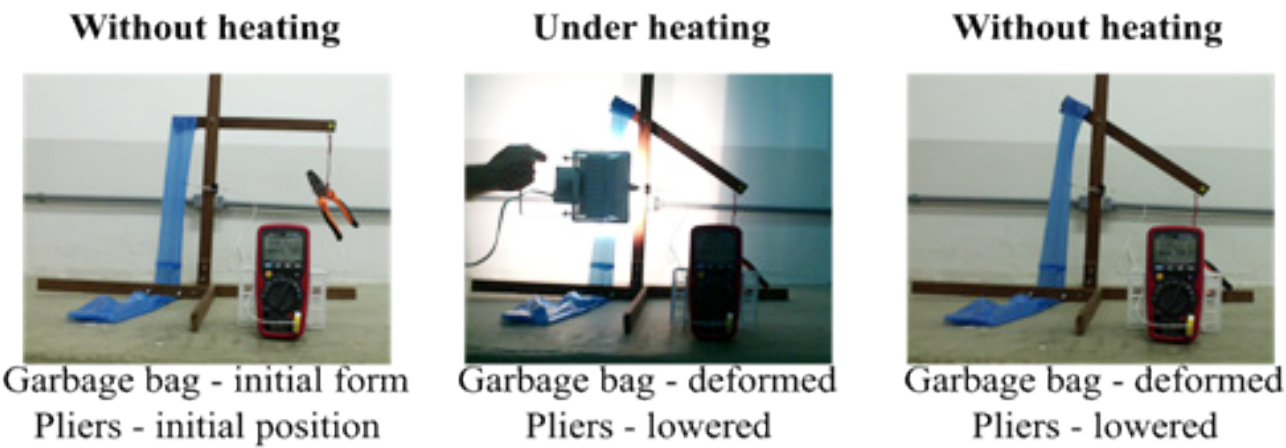

Figure 1. Garbage bag's behavior.

Their responses were registered on an observation record (data source D1). After a rapid conversation about their records, the heating (approximately $60^{\circ} \mathrm{C}$ ) was initiated and the behavior of the system was observed (Figure 1).
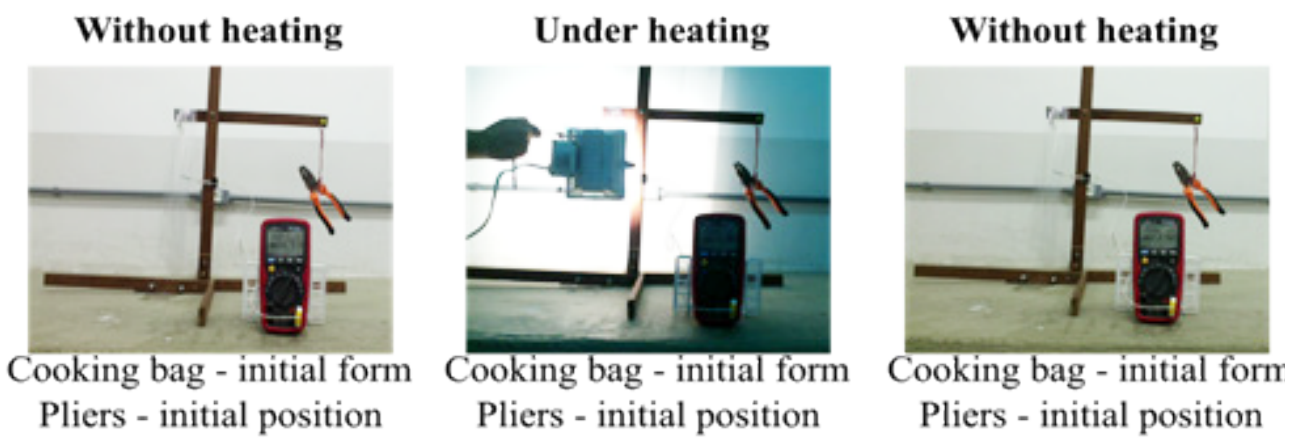

Figure 2. Cooking bag's behavior.

At the end of demonstration, students had to describe and explain the observed facts (data source D2). These steps were repeated for the other materials, respectively cooking bag (Figure 2) and condom (Figure 3).

Without heating

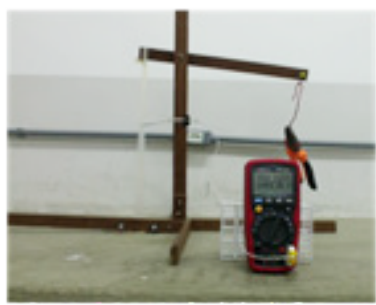

Condom - initial form

Pliers - initial position
Under heating

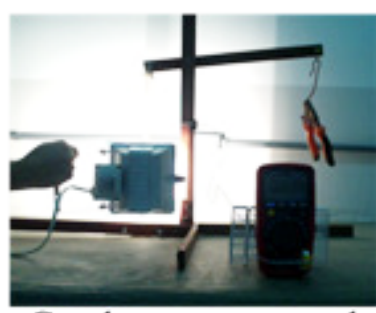

Condom - contracted

Pliers - lifted
Without heating

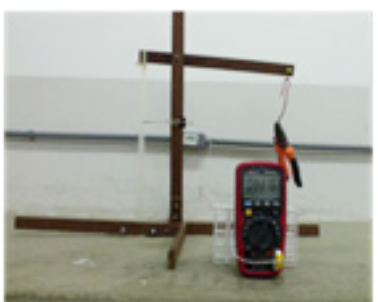

Condom - initial form

Pliers - initial position

Figure 3. Condom's behavior. 
After the students recorded verbally their explanations (written text), the main aspects of a video with successive images magnified by optical and electronic microscopy were described. The video was Zoom into Plastic (Sizemore, 2016) with $3 \mathrm{~min}$. and 09 sec. and, for this, previously a free translation into the Portuguese language was elaborated and a narration was recorded and reproduced in a synchronized way. In this moment, the idea of a model in science was discussed, emphasizing the limits of observation to the naked eye (reality and representation of reality), the role of physical-chemical data for the creation of scientific images and the role of chemical theories in the creation of theoretical models. Although it was done by conversations, Gilbert (2008, p. 19) argues that these moments are important in the practice of visualization and strategies should be elaborated to develop both students' conceptions about nature of scientific knowledge and of scientific model.

Next, first scientific notions about polymers were presented to students, that is, formation of macromolecules (polymer chain) from monomers and its intermolecular interactions. Given the molecular representations of stick-and-ball (2D), created with ChemSketch and ChemViewer softwares of ACD Labs (2010) and organized in Impress (from the LibreOffice suite), type of polymer fragments that constituted each of the samples such as polyethylene (garbage bag), polyethylene terephthalate (cooking bag) and of cis-1,4polyisoprene vulcanized (condom) was asked them to propose a polymer chains' model of organization in function of its intermolecular forces, of observed behaviors and simplifying each chain by a drawn line with the pen (data source D3), without the atoms or functional groups but maintaining cross-links in the case of the latex (vulcanized rubber).

After this moment, the scientific concepts were taught through a dialogical exposition starting from presentation of the spaghetti representation for amorphous (random distribution) and crystalline (linear distribution) domains of the polymeric materials. To create a connection between the concrete and abstract aspects of these representations each student used a piece of parafilm (plastic paraffin film of $2 \mathrm{~cm} \mathrm{X} 4 \mathrm{~cm}$ ), a blank CD without its outer layer and a laser pointer.

The students placed a piece of parafilm at a distance of $1 \mathrm{~cm}$ from the observation sheet and read one of the written words. Then, holding with fingers the central part and one end of parafilm they stretched this half of material. When they tried to read the same word from the observation sheet through of a parafilm stretched part they could perceive that image was blurred and the word could not be viewed as before. In turn, the laser pointer was used to experience the diffraction of monochromatic light caused by its traversing through the relatively parallel tracks of the thin spiral (630 tracks per millimeter) printed on the CD. Then, by analogy, the stretched half of parafilm blurred the image by the fact of diverting white light from its path (as a "diffraction") due to an organized internal structure (crystalline region), while the absence of this degree of organization (amorphous region) facilitated the passage of white light, evidenced by the reading of word printed on the sheet through of normal half of parafilm.

In this way, the basic polymer concepts were discussed and taught in the sense to relate concrete aspects involved in the experimental demonstration with the abstract aspects (chemical theories and representations). A static spaghetti-like representation (see later, in Figure 5) was used together with an animated spaghetti-like representation obtained from Tschopp (2010). For instance, the Wan der Waals forces present in inter- and intra-chain interactions of polyethylene did not prevent the displacement of the linear polymer chains which explain the deformation of the garbage bag with the addition of heating. 
On the other hand, the hydrogen bonds (strong interactions) present in inter- and intra-chain interactions of polyethylene terephthalate contributed to explain the fact that the cooking bag resists to deformation during heating (its average melting point exceeds $200^{\circ} \mathrm{C}$ ), although it is an apparently fragile material. The condom, which was placed purposely stretched in the wooden device, has cross-links between its polymer chains and this theoretical model helps to explain both its return movement to the initial state (reversibility) and the fact that when it is stretched (formation of crystalline domains) the energy is released, and the addition of more heat (by $500 \mathrm{~W}$ lamp) promotes its contraction (formation of amorphous domains), a fact that explains the rise of the pliers in the device.

At the end the animation developed by Banerji and Tausch (2011) was exhibited to apply concepts of quantum chemistry in the polymeric phenomena related to basic functioning of an OLED (organic light-emitting diode) and together they would explain the initial question. In short, if the plastic nature of polymer materials can be explained by the movements between its chains (as OLED screen's flexibility) on the other hand its capacity to conduct electricity (which makes screen work) and to emit light (to formation of image) are explained by the transitions of the Pi electrons that linking its carbon atoms.

This animation was presented together with a dialogical exposition and for closing of this sequence a small questionnaire was implemented constituted by one objective question in which students chose a pictorial representation to explain each observed behavior (data source D4) and its respective explanation through a written text (verbal form).

\section{Teaching-Learning Sequence of Photopolymer}

In the initial moments, a short history was presented about miniaturization of the electronic components emphasizing the passage of diode valve to transistor and from the latter to the integrated circuits (Chip). Using Moore's law as a background, the capacity for miniaturization was illustrated through technological developments since Intel 4004 chip, commercialized in 1971, with 2,300 transistors in a $12 \mathrm{~mm}^{2}$ of surface until Intel Broadwell-E5 chip, of 2016, containing approximately 7,200,000,000 of transistors in a surface of $456 \mathrm{~mm}^{2}$.

The students were invited to, first, observe by naked eye a chip (approximately 3,2 $\mathrm{mm}$ X 2,4 mm) obtained from within a SIM Card (used in cell phones) and then a brief sequence of images showed its magnification up to 1750 times the original size (Mišeikis, 2010). But again, images by optical microscopy only problematized the fact that the modern chip's resolution, of its transistors and tracks, is on the order of 50 nanometers or less and its "visualization" is obtained by electronic microscopy. This is necessary to withstand that high transistor density, that is, 15 million per square millimeter or more.

Once this context was created, a question was realized: How can polymer chemistry be involved in the achievement of this nanometric scale of "conductive tracks" through which transistors link together? After a free discussion on the students' responses, they were invited to observe an experiment constituted by two kinds of samples, transparent school glue and a resin used in the manufacture of stamps. Three pairs of samples (glue and resin) were formed. Each pair of samples was submitted, simultaneously and separately, to three different environments and inside pre-built boxes, that is, under the absence of light, under the action of a red light (red lamp) and under ultraviolet light (black light lamp), as shown in Figure 4C. 
Using an observation sheet, the students recorded initial characteristics of school glue and resin for stamps, both starting from a viscous appearance (viscous will be considered as: More viscous than water). After 3 minutes of exposure, the samples were observed, and their final states were noted. There were no significant changes in the samples that were under the red light's action and in the absence of light. The change was observed in the UV light's action once school glue did not change, remaining in the form of viscous liquid (Figure 4A), but resin of the stamp changed from a viscous liquid to an elastic material's form, a rubber (Figure 4B). Then a paper and pencil task was implemented, in which they had to explain the result of the action of the UV lamp on the two samples, using drawings and written text (data source D5).

The students' answers were discussed and the presentation of the chemical concepts on polymer reactions was initiated. Using stick-and-ball representations (2D) for the polymer chains' fragments involved in experiment, it was explained on the one hand that polyvinyl acetate (the main constituent of school glue) did not undergo transformations in its polymer chains and the perception of the decrease of sample viscosity under red light's action ("increase" of temperature) would have been favored by evaporation of a little of solvent (water), in other words, by functioning of the glue itself, in short, evaporation of water promoted an approximation more effective between the polymer chains (and a strong linkage between them), decreasing material viscosity.

The similar idea can be found to polymer solutions, in Teraoka (2002):

In the solid state, polymer molecules pack the space with little voids either in a regular array (crystalline) or at random (amorphous). The molecules are in close contact with other polymer molecules. In solutions, in contrast, each polymer molecule is surrounded by solvent molecules (Teraoka, 2002, p. 01).

On the other hand, the stamp resin consisted mainly of urethane-acrylate oligomers ("large" monomers), monomers and a photoinitiator. Any molecule that functions as a photoinitiator is reactive with a given wavelength (in this case, it is sensitive to UV radiation) and such an interaction "divides" the molecule into two radicals, which are highly reactive. These radicals react and bond to oligomer's acrylate region, which in turn becomes a radical and bonds to another oligomer, producing a chain reaction between acrylate groups and, thus, the polymer chains (of oligomers and monomers) "sew" each other and forming a network of cross-links, producing a structure that explains their elastic properties, a rubbery material.

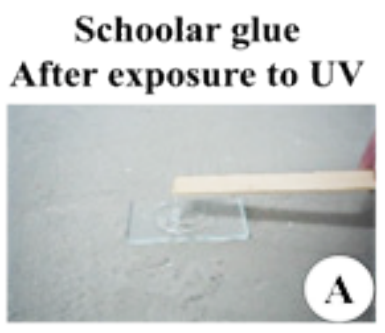

Final form:

Viscous liquid

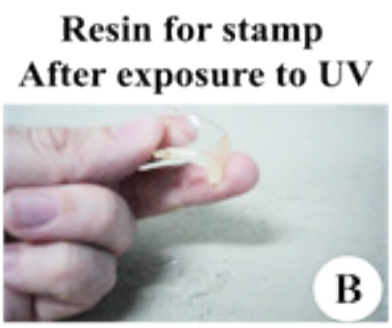

Final form:

Elastic material
Equipaments

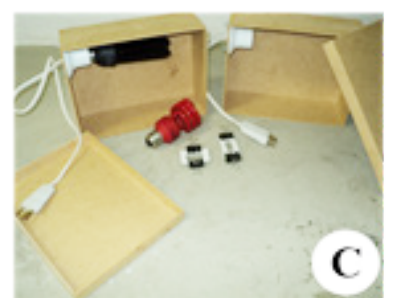

Wooden boxes, red and UV lamps and sample holders

Figure 4. Glue and resin for stamp's behavior. 
After the use of the stick-and-ball representations, which allowed us to approach concepts related to the involved substances' intermolecular interactions, the spaghetti-like representations were reintroduced. The explanatory models understand that many polymers show partially crystalline, they present both crystalline and amorphous regions in their structure, while non-crystalline polymers are those which presenting high levels of irregularity within their structure (amorphous regions).

Thereby, the spaghetti-like representations (with random and regular distributions) can contribute in learning of abstract concepts about polymer phenomena (including aspects as size and kind of chain, average molecular mass). In the intriguing phenomena of UV light's action on resin of stamps (turns the viscous liquid into an elastic material) and of latex elasticity (once stretched, when heated it is able to lift pliers) the model of spaghetti-like representations with cross-links are important to explain, respectively, both formation of cross-links and reversibility between the induced crystalline structures and the amorphous structures in these rubbers (Figure 5) because according to Nicholson when “... a rubbery polymer, such as natural rubber, is stretched the molecules become aligned. This orientation leads to crystallization. [...] Such crystallization is not permanent but disappears when the sample is allowed to retract and regain its original dimensions (Nicholson, 2006, p. 44)".
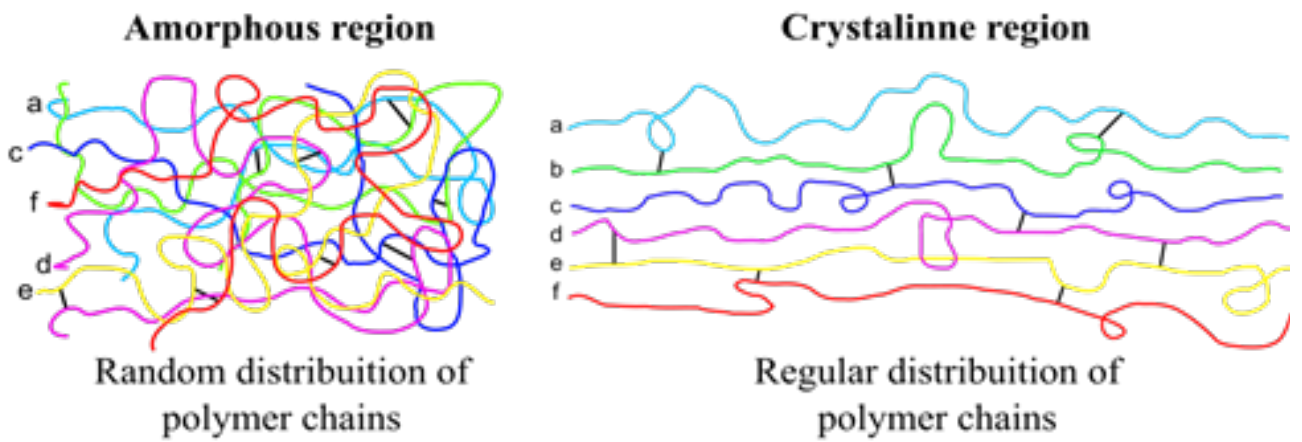

Figure 5. Spaghetti-like representations for a rubber (not stretched and stretched).

After the concepts on polymer reactions (including photopolymerization) were approached and materials' properties were analyzed using spaghetti models, a return to the initial question was made because photopolymerization reactions are not only used in paints, coatings, varnishes, adhesives, in the production of optical lens surfaces, in dermatological treatments and in dental restorations, but have also been used in microelectronics. If on the one hand UV light's action on resin of stamp turned it into a rigid material (a negative photoresist) on the other hand, a polymeric material that when UV light's action dissolves it (a positive photoresist) is used in chip fabrication.

Then, a brief video was exhibited with the original narration replaced by that of the researchers. The previously selected fragments lasted $4 \mathrm{~min}$. and $35 \mathrm{sec}$. and were obtained in Amiri (2016). Through it the main steps of chip's manufacture was shown with special attention to the role of the photopolymer in this process, represented in the video by an animation. At the end a small questionnaire (data source D6) was implemented constituted by one objective question (with spaghetti-like representations) and its respective explanation through a written text both to explain each observed behavior. 


\section{Research Methodology}

\section{Participants}

In this exploratory research, the participation of undergraduate Chemistry students was voluntary. From a total of 43 participants, only 34 of them had their records analyzed because six students realized tasks of D1 to D3, six completed tasks of D1 to D5 and twenty- two realized all proposed tasks. The students' names were coded to preserve their anonymity.

\section{Instruments}

The data collection instruments were constituted by students' records in observation sheets. The tasks with paper and pen, in first teaching-learning sequence, were: Prediction of samples' behavior in latex lift (D1); their descriptions and explanations (D2); proposition of an explanatory model using one drawn line for each polymer chain (D3) and a small questionnaire with objective and essay questions (D4). In the second teaching-learning sequence, the records consisted of: An explanation of UV light's effect on school glue and on resin of stamp using written text and the mobilization of spaghetti-like representations using drawings (D5) and a small questionnaire with objective and essay questions (D6).

\section{Data Analysis}

The analysis of the student responses was inspired by Content Analysis. The materials (pictures and written texts) were digitized (scanned and transcribed, respectively) and, after their codification, a vertical (all answers for the same question) and other horizontal (all responses of the same student) floating reading were performed (Bardin, 1977).

Then, answers' categorization was carried out in the light of the spaghetti-like representation (for picture form) and the mobilization of words related to chemical and polymeric concepts (for verbal form), in order to conjecture about their approximations and deviations in relation to the scientific model. The elaborated categories were discussed through alternative conceptions and scientific conceptions about polymer chemistry, as well as, a general analysis of the two demonstrations was carried out by a theoretical reference on the role of experimentation in teaching of sciences.

\section{The Results Obtained from The Students' Answers}

According to the student's registers categories were created to each experimental demonstration. While Table 1 shows the results obtained by student's written texts (verbal form), in Table 2 they were based on their respective drawings (pictorial form).

In table 1, on the part of the Latex lift demonstration, the category named by correct prediction presents the students' correct answers and they are classified according to the nature of the argumentation used, that is, if only everyday concepts (non-scientific concepts and in its concrete aspects), chemical concepts or polymer concepts were mobilized through words and phrases (evidences of scientific concepts). Below, the incorrect answers were presented without a detailed classification. In the same way, in the category denomi- 
nated by coherent explanation the correct answers are presented and the same classification to arguments' content was assumed. The incorrect explanations are also presented but aren't classified.

Table 1. Conceptions obtained by demonstrations and their frequencies (verbal form).

\begin{tabular}{|c|c|c|c|}
\hline \multirow[b]{2}{*}{ Categories } & & \multicolumn{2}{|c|}{$\begin{array}{l}\text { Latex lift demonstration } \\
\text { Frequency }(N=34)\end{array}$} \\
\hline & & Garbage bag & Condom \\
\hline Correct prediction: & Using only everyday concepts & 30 & 03 \\
\hline & Using some chemical concept & 04 & 0 \\
\hline & Using some polymer notion & 0 & 0 \\
\hline Incorrect prediction & & 0 & 31 \\
\hline Coherent explanation: & Using only everyday concepts & 20 & 26 \\
\hline & Using some chemical concept & 01 & 05 \\
\hline & Using some polymer notion & 07 & 03 \\
\hline Incorrect explanation & & 06 & 0 \\
\hline & & \multicolumn{2}{|c|}{$\begin{array}{l}\text { Photopolymer demonstration } \\
\text { Frequency }(N=28)\end{array}$} \\
\hline & & School glue & $\begin{array}{l}\text { Resin of } \\
\text { stamp }\end{array}$ \\
\hline Correct explanation: & Using only macroscopic aspects & 15 & 11 \\
\hline & Using polymer concepts & 02 & 04 \\
\hline Incomplete explanation & (Using polymer concepts) & 04 & 07 \\
\hline Incorrect explanation & (Using polymer concepts) & 07 & 06 \\
\hline
\end{tabular}

Still in Table 1, on the Photopolymer demonstration's part, the students' responses appear firstly under the correct explanation category which shows the frequency of answers based only on macroscopic aspects (concrete aspects) and those that have mobilized polymer concepts (abstract entities). The incomplete explanation category contained the answers which partially mobilized polymer concepts, for instance, like student TU08 wrote: "The resin of stamp has a behavior similar to that of latex, that is, it has strong crosslinks which give the material an elastic behavior". This student perceived the cross-linking model to explain the behavior but was not able to explain why these elastic characteristics were not present in the initial resin shape (the cross-linking process was not perceived). In the category incorrect explanations, the polymeric (or chemical) concepts were used in the wrong way.

In Table 2A, with data related to the Latex lift demonstration, the students' drawings were categorized as to the represented chains' shape (wavy, zigzag and straight lines) and all of them were disposed in parallel. In addition, explanatory evidences for polymer be- 
haviors were sought from the correlations (differences and similarities) between the drawn chains for the initial and final states of samples, including the relationships between each chain. In short, chain's shortening or stretching from one state to another or its dividing into smaller chains formed explanatory clues based on changes in the bonds between atoms (criterion of chemical bonds).

The variations of the distances between the drawn chains were also observed and served as explanatory criterion (criterion of interchain distances) as well as the attempt to representing chains with larger and smaller undulations (criterion of waviness chain). The latter represented a prior idea similar to "folding" and "unfolding" and necessary for spaghetti-like representations' understanding (respectively, amorphous and crystalline domains).

Table 2A. Conceptions obtained by demonstrations and their frequencies (pictorial form).

\begin{tabular}{|c|c|c|c|c|}
\hline Categories & & & $\begin{array}{c}\text { Latex lift } \\
\text { demonstration } \\
\text { Frequency }(N=34)\end{array}$ & \\
\hline Chain's form: & & Wavy lines & 24 & \\
\hline Zigzag lines & & & 7 & \\
\hline Straight lines & & & 3 & \\
\hline Chain's deployment: & Parallel & & Garbage bag & Condom \\
\hline $\begin{array}{c}\text { Explanatory criterion of } \\
\text { chemical bonds: }\end{array}$ & & & 10 & 5 \\
\hline Shortening & & Elongation & 0 & 3 \\
\hline Rupture & & & 1 & 0 \\
\hline Rearrangement & & $\begin{array}{c}\text { Increase } \\
\text { distance }\end{array}$ & 8 & 2 \\
\hline $\begin{array}{c}\text { Explanatory criterion of } \\
\text { interchain distances: }\end{array}$ & & & 1 & 24 \\
\hline Decrease distance & & Increase & 0 & 0 \\
\hline $\begin{array}{c}\text { Explanatory criterion of } \\
\text { waviness chain: }\end{array}$ & & & 8 & 0 \\
\hline Decrease waviness & & & & \\
\hline
\end{tabular}

In its turns, in Table 2B, related to the Photopolymer demonstration, when the students had to mobilize the spaghetti-like representation's model, the data about the students' drawings were categorized differently for the glue and for the resin of the stamp, because these samples presented different behaviors among themselves and in relation to those observed in the first demonstration. Then, for the school glue, the correctly mobilized models were categorized as complete representation and those models that preserved the characteristics of the personal models (created by the students themselves) were categorized as alternative representation. Below, the last category adds students who did not draw. 


\section{Tarefa 2: Com base nos seus conhecimentos elabore um modelo, em nivel submicroscópico (e fazendo desenhos), para explicar as propriedades da resina de carimbo e da cola escolar observadas depois dos experimentos:}

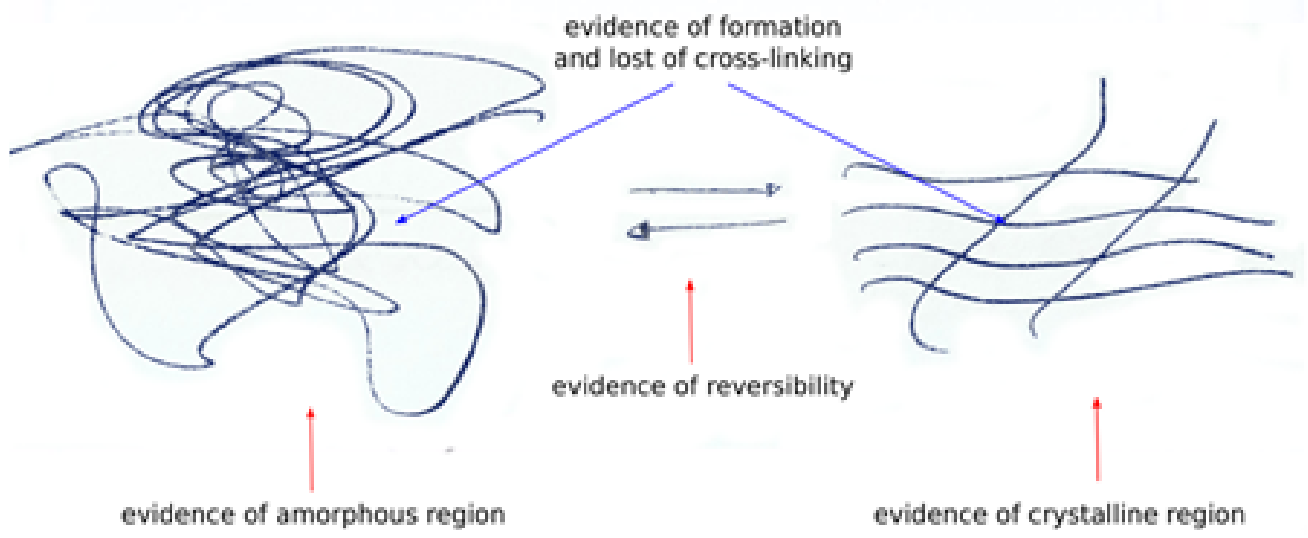

Figure 6. Student's representation of formation and lost cross-linking.

For resin of stamp, the models correctly mobilized but did not contain one or more aspects or that added incoherent aspects were categorized as incomplete representation. In the first case, the models that did not represent the cross-linking and did not use the amorphous-crystalline reversibility to explain the elasticity of the rubber (formed from the resin) can be found. In the second, there were the models that represented the cross-linking in resin, without perceived that the resin (before the UV light's action) did not assume an elastic behavior (rubber).

In another instance, the student TU22 attempts to resolve this impasse through creation of a model in which the cross-links are formed and undone (Figure 6, above). In alternative representation category, the permanence of models created by own students and their respective characteristics are presented. 
Table 2B. Conceptions obtained by demonstrations and their frequencies (pictorial form).

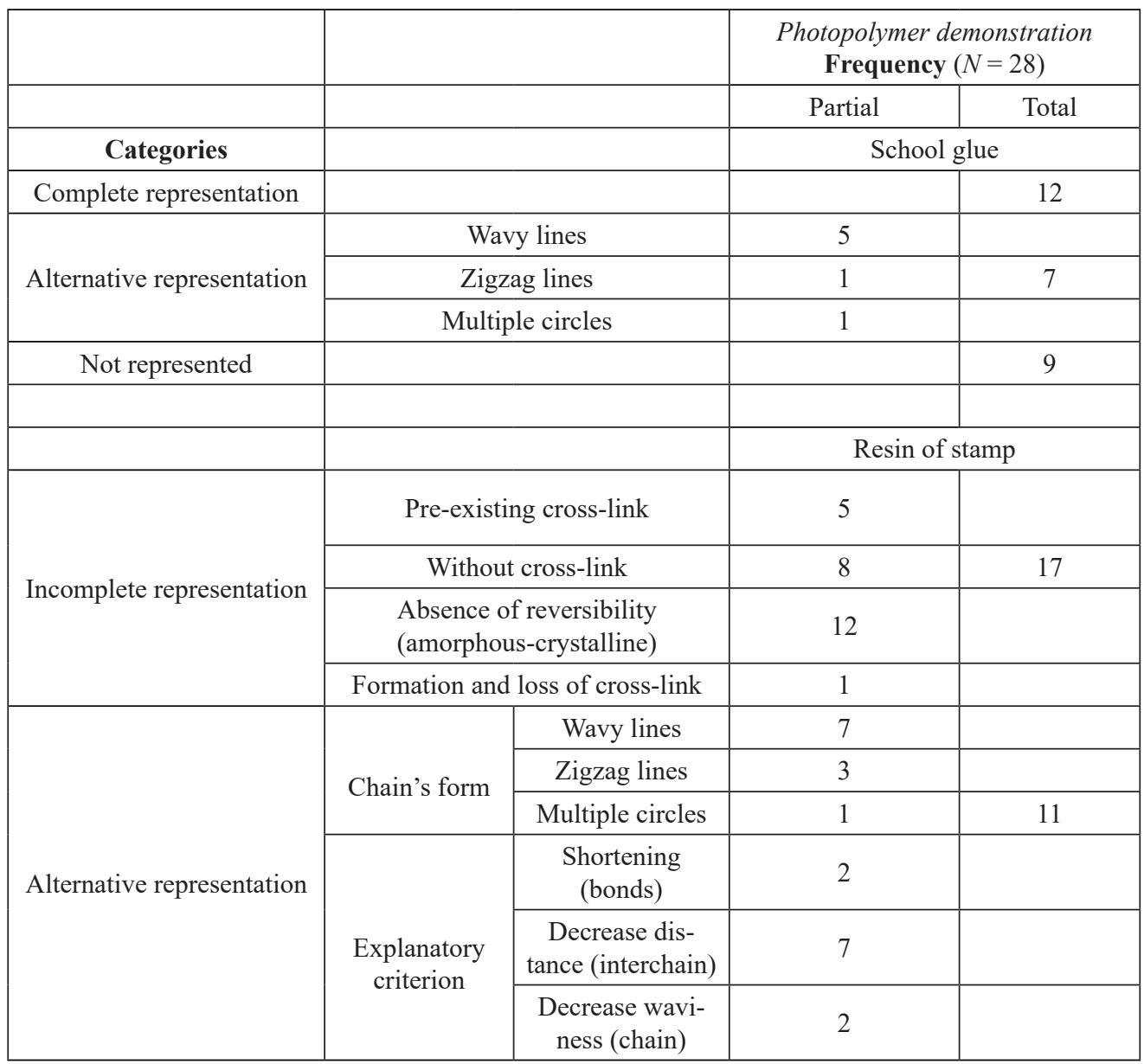

The Table 3A and the Table 3B compile the data obtained through two small questionnaires implemented after the first and second teaching-learning sequences. More clearly, for each of the five samples (condom, garbage bag, cooking bag, resin of stamp and glue for school) a written question was posed for students to explain its physical behaviors, for instance: Which option best describes the behavior of the condom in the elevator experiment? Below, three photos were displayed to illustrate the initial (unheated) state of the system, the intermediate state (with heating) and the final state (unheated), similar to Figure 1. Below these figures, a list with four options (from A to D) consisting of three spaghetti representations for each of the photos was made available. After choosing the option, students should write a text explaining the material's behavior and using the representations as an auxiliary medium. 
Table 3A. Students' responses to the first small questionnaires.

\begin{tabular}{|c|c|c|c|c|c|}
\hline & & & \multicolumn{3}{|c|}{$\begin{array}{c}\text { Questions about latex lift } \\
\text { demonstration } \\
\text { Frequency }(N=28)\end{array}$} \\
\hline Categories & $\begin{array}{c}\text { Objective question } \\
\text { (Pictorial) }\end{array}$ & Essay question (Verbal) & Condom & $\begin{array}{c}\text { Garbage } \\
\text { bag }\end{array}$ & $\begin{array}{c}\text { Cooking } \\
\text { bag }\end{array}$ \\
\hline $\begin{array}{c}\text { Correct } \\
\text { responses }\end{array}$ & $\begin{array}{c}\text { The correct spaghetti- } \\
\text { 1ike representations } \\
\text { were chosen }\end{array}$ & $\begin{array}{c}\text { The written text } \\
\text { was coherent and } \\
\text { complementary with the } \\
\text { pictorial representations }\end{array}$ & 25 & 27 & 27 \\
\hline $\begin{array}{c}\text { Incorrect } \\
\text { responses }\end{array}$ & $\begin{array}{c}\text { The correct spaghetti- } \\
\text { like representations } \\
\text { were chosen }\end{array}$ & $\begin{array}{c}\text { The written text was } \\
\text { not coherent with the } \\
\text { pictorial representations }\end{array}$ & 1 & 1 & 0 \\
\cline { 2 - 6 } & $\begin{array}{c}\text { The incorrect } \\
\text { spaghetti-like } \\
\text { representations were } \\
\text { chosen }\end{array}$ & $\begin{array}{c}\text { The written text was } \\
\text { not coherent with the } \\
\text { question }\end{array}$ & 2 & 0 & 1 \\
\hline
\end{tabular}

In the first part, coherent articulation between the chosen option and the written text was categorized as correct responses while incorrect responses category was formed by written texts that did not correctly justify the checked option and also those that, in its turn, chose an incoherent option and its written text did not coherently explain the observed phenomena. In the second part, the previous categories were retained and a third (incomplete responses) was added. This was due to the fact that a part of the students correctly explained (articulating pictorial representation and written text) the rubber elasticity formed after the UV light's action but not bringing to this partial explanation a model for the resin of stamp in its colloidal form (viscous liquid).

Table 3B. Students' responses to the second small questionnaires.

\begin{tabular}{|c|c|c|c|c|}
\hline & & & \multicolumn{2}{|c|}{$\begin{array}{c}\text { Questions about } \\
\text { photopolymer demonstration } \\
\text { Frequency }(N=22)\end{array}$} \\
\hline Categories & $\begin{array}{c}\text { Objective question } \\
\text { (Pictorial) }\end{array}$ & Essay question (Verbal) & $\begin{array}{c}\text { Resin of } \\
\text { stamp }\end{array}$ & School glue \\
\hline $\begin{array}{c}\text { Correct } \\
\text { responses }\end{array}$ & $\begin{array}{c}\text { The correct spaghetti- } \\
\text { like representations were } \\
\text { chosen }\end{array}$ & $\begin{array}{c}\text { The written text } \\
\text { was coherent and } \\
\text { complementary with the } \\
\text { pictorial representations }\end{array}$ & 7 & 22 \\
\hline $\begin{array}{c}\text { Incomplete } \\
\text { responses }\end{array}$ & $\begin{array}{c}\text { The spaghetti-like } \\
\text { representations with pre- } \\
\text { existing cross-links were } \\
\text { chosen }\end{array}$ & $\begin{array}{c}\text { The written text explained } \\
\text { the correct behavior but } \\
\text { based on cross-links' pre- } \\
\text { existence in the resin }\end{array}$ & 11 & 0 \\
\hline $\begin{array}{c}\text { Incorrect } \\
\text { responses }\end{array}$ & $\begin{array}{c}\text { The incorrect spaghetti- } \\
\text { like representation was } \\
\text { chosen }\end{array}$ & $\begin{array}{c}\text { The written text was not } \\
\text { coherent with the question }\end{array}$ & 4 & 0 \\
\hline
\end{tabular}




\section{Discussion}

In order to answer the central question of this work, that was: How can the use of spaghetti-like representations be explored to problematize basic concepts of polymer chemistry?, two demonstrative experiments were used as a starting point for the drawing practices (construction and externalization of explanatory models), each within a teachinglearning sequence. Therefore, the results will be presented and related to both demonstrations.

\section{Latex Lift Demonstration}

Table 1 showed that students' incapacity to predict correctly the system (the pliers will come down or not, or nothing will happen) as a function of each sample increased from 0 for garbage bag to 25 and 31 for cooking bag and condom, respectively. Since the experiments are not intrinsically motivating and conducive to learning, the adaptation accomplished (the inclusion of two samples) could contribute to some aspects enunciated by Galiazzi and Gonçalves (2004, p. 328-330): i) The strengthening of predictions' practice because of the caused expectation and dissatisfaction with the outcome, and doing students to question and perceive gaps in their own understandings; ii) showed the "mark of the surprising" insofar as the behavior of the condom caused astonishment of the majority of the students. Obviously, this wasn't a not contextualized surprise since scientific knowledge was later addressed within TLS.

Still, as a consequence of previous items, the demonstration assisted in iii) the exposure of knowledge of each of the participants since it was succeeded in getting the students to mobilize their prior knowledge to explain each of the phenomena although their answers have remained at the level of everyday concepts (based on concrete aspects). Out of a total of 34 responses (in Table 1), 20 used only everyday concepts to explain garbage bag, 18 for cooking bag and 26 for condom. As an example, students explained garbage bag's behavior in this way: "The material began to melt, as expected, and stretched due to the pliers, attached to the other end, to exert a force causing it to stretch, increasing its size and making it more flexible (TSA2)".

After this moment, the students have known fragments of polymer chains that constituted each sample through 2D representations of stick-and-ball type, they proposed a model to explain the three different behaviors observed. Table 2A shows that the most used chain form (when $N=34$ ) was wavy-like (24) and the second most used was zig-zag type (7). The latter form illustrates the permanence of known representations in the elaboration of new ones, because a line drawn between the atoms of fragments (under stick-and-ball representation) resembles a zigzag, mainly for polyethylene. This path is mentioned and represented like a resource teaching by successive figures in Teraoka (2002) which scroll through: i) "simplification of chain conformation from an atomistic model"; ii) "to mainchain atoms only" iii) "and then to bonds on the main chain only"; iv) "and finally to a flexible thread model (Teraoka, 2002, p. 04)".

The deployment of each chain was only in parallel, revealing evidence of difficulty of "giant" molecules and their interchain interactions being thought to promptly arise a tangled chains' configuration. It is important to consider that even for Chemists there was a certain resistance to think the existence of a theoretical model based on long chains of atoms when the History of Chemistry is visited. Since Thomas Graham's work in 1861 on 
colloidal phenomena, the function of particle size has been placed and its nature has been debated.

In a very general way, according Zandvoort (1988, p. 489-505) while the proponents of a chemical approach for colloidal behavior was based on dimensions of the individual molecule, a physical approach denied a direct link of this behavior to the structure of the molecules and their sizes, since the particles could be formed by an aggregate of a large number of molecules, united by physical forces of cohesion.

For instance, Carl Harries, in 1905, proposes that the structure of the natural rubber was a small ring formed by two units of monomers, which was added to the other rings by forces of cohesion. This rich and complex History shows that Hermann Staudinger's vigorous work between 1920 and 1935 helped reintroduce a long chain view, which was aided by the evidence produced by Wallace Carothers on the analysis of polymerization products (originated naturally or by synthesis) (Zandvoort, 1988, p. 505).

In this sense, although an entangled chain was not found in these first models elaborated by students, indications of three explanatory criteria were represented. The criterion of distance between the chains (32) was most frequent, followed by the criterion of the chemical bond and the criterion of the waviness chain (12). In Figure 7, examples of criteria can be found for garbage bag's behavior, while students TSA3 and TU11 suggest rupture of chemical bonds, TSB5 present the increase of interchain distance. Indications of chemical bond's elongation are brought by TU12 while a model close to unfolding (decrease of waviness chain) is brought by TU12.

Interestingly, for garbage bag's behavior, the most of occurrences were elongation of chemical bond (10), decrease waviness chain (08) and increase distances between chains (08). The first two seem to suffer the influence of the macroscopic deformation observed, as a force that stretches and unravels both the material and the macromolecules, whereas in the third criterion the chains seem to have imagined in a horizontal sense, so deformation would be explained by the increased distance of parallel chains from each other. While for condom's behavior most of the drawings assumed the decrease of interchain distances (24), which seems to have been influenced by contraction of the material, in the second highest occurrence (05) drawings mobilized the criterion of chemical bonds elongation, not following the influence of the macroscopic level. 
TSA3

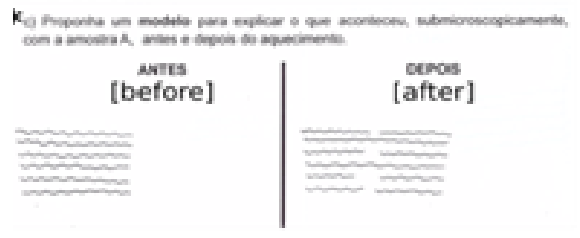

TU11

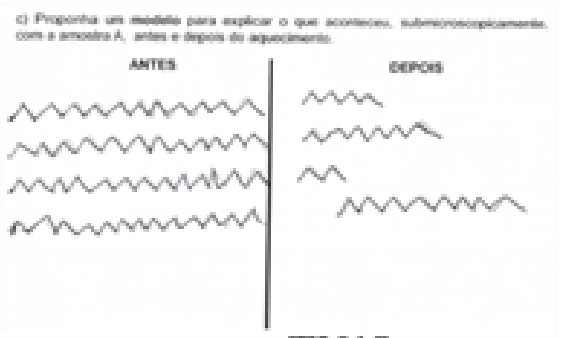

TSB5

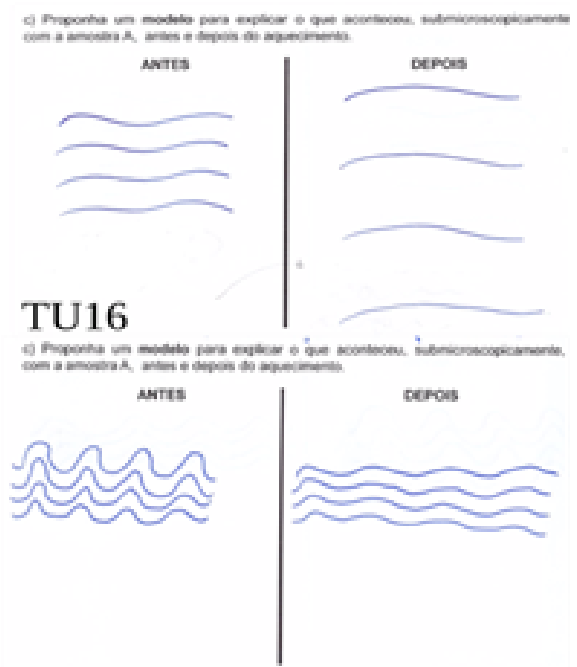

\section{TU12}

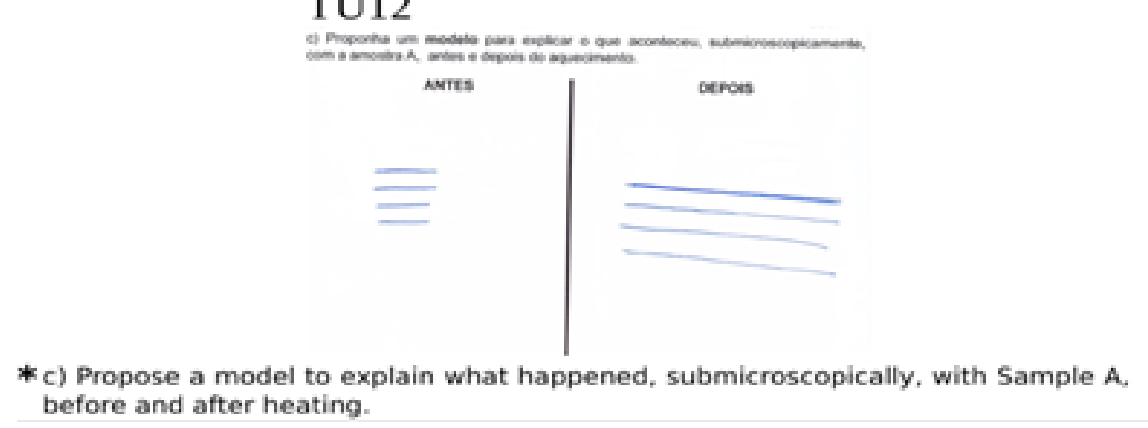

Figure 7. Student's representation for chain's forms and explanatory criteria (garbage bag's behavior).

These results resemble those found in the context of the teaching of polymers with students of Engineering. According to Kelly, Krause and Baker (2010), misconceptions that lead to an incorrect understanding about stretching of polymer chains or bonds were frequent. Some students "stated that, during the macroscopic stretching of the rubber band there was also microscopic stretching of the polymer chains instead of bond rotation", some "believed bonds are stretched or bent [physically]" and "intermolecular bonds stretched, covalent layers pulled further apart (Kelly, Krause, \& Baker, 2010, p. 05)”. In this sense, another paper, according to Kelly, Heinert, Triplett, Baker and Krause (2010), reports that students can say "stretching polymer chain" and or "chains elongate". However, the authors recognize that "misconceptions have not yet been documented about student understanding of polymer behavior, properties or deformation mechanisms (Kelly, Heinert, Triplett, Baker, \& Krause, 2010, p. 05)".

At the end of this first teaching-learning sequence, a small questionnaire was implemented. The students had to recognize and choose a model of spaghetti-like representation that would assist them in mobilizing the polymer concepts needed to explain material behavior of samples. The data in Table 3 show that most students (when $N=28$ ) correctly answered the questions, reaching a score of 25 for a condom, 27 for a garbage bag and 27 for a cooking bag. This performance will fall to the end of the second teaching-learning sequence. 


\section{Photopolymer Demonstration}

The photopolymer demonstration was designed to have the function of medium for the application of knowledge and, so, predictions of the phenomena were not realized, only observation and subsequent explanation based on the polymer concepts taught previously. In Table 1, it is possible to see that the correct answers of students $(N=28)$ remained based on the macroscopic aspects ( 15 for school glue and 11 for resin of stamp) rather than abstract concepts (as indicated by the used terms and phrases).

On the other hand, the mobilization of knowledge on polymers was greater than in the first demonstration, but it was incompletely ( 04 for school glue and 07 for resin of stamp) or incorrectly used ( 07 for school glue and 06 for resin of stamp). In citations below, while the first student presented a correct response, the second elaborated a response considered incomplete because the formation of cross-links wasn't considered (they were pre-existent in resin). The third student's response represented an incorrect way because polymer idea has been reduced to only a decrease of space between polymeric chains (without the cross-linking) for the rubber obtained by resin's vulcanization.

The radiation effect was different on the two substances, both suffered greater effects of the black light, which triggered a formation of cross-linking in resin's structure, giving form and flexibility. In the case of glue only viscosity increased but didn't occur cross-linking (TSB3).

It was observed that the resin presented elasticity when submitted to UV light. It behaved as an elastomer; it assumed some properties as flexibility. With the action of light there was a contraction due to cross-bonding which favors elasticity and also it took on solid form, "more together" [...] (TU21).

Apparently, the wavelength emitted by the light is related to the changes presented by the materials. The agitation in the molecules, modifying their geometries made the polymers have opposite characteristics. It made the macromolecules cluster even further, changing the physical state of the material [...] (TSA2).

It showed that the demonstration was more complex for students because it addressed a polymer reaction not yet taught at this time of short course, besides presenting samples of polymers and oligomers in form of colloidal dispersions. It is important to not fix understandings only in amorphous solids (such as garbage bags, cooking bags and condoms) but, on the other hand, it provoked an attempt to use (or adjust) the concepts learned earlier in the explanation of new phenomena. According to Sweller et al. (2011), students in the face of a new problem mobilize (by random and efficiency test processes) the schemes (knowledge) previously stored in their long-term memories. One of them was the transposition of the model of the reversibility of the amorphous and crystalline domains of the elasticity of rubber (condom) for the explanation of transformation of resin to rubber, as can be seen below.

As it was observed, under black light, the resin had a behavior similar to latex, since there was polymer in the material, elastic characteristic, and with the addition of light energy the equilibrium was shifted to the amorphous form. Elastomers have cross-linking (TU13). 
Mainly, in addition to the "mark of the surprising", provoked by capacity of UV light in transform a very viscous liquid into a rubber, the demonstration acquired a problematizing characteristic since most of the students could not correctly explain all phenomena from their previously learned and, according to Oliveira (2010), the demonstration was placed in a new ZDP, close to polymer properties but away from the concepts of polymerization reaction and forms of colloidal dispersion, since "each type of activity, with its respective and gradual difficulties, contribute to the intellectual development of students, leading to advances in learning (Oliveira, 2010, p. 40)".

After they explained the phenomena using a written text, the students made explanatory models using drawings. Table 2B shows, for school glue (when $N=28$ ), that while 12 students made a coherent representation (did not use cross-links and tried to make long, entangled or little symmetrical), 07 students remained with their old representations, elaborated during the first teaching-learning sequence. Nine students forgot or did not want to represent.

\section{TU14}

* Tarefa 3: Com base nos seus conhecimentos elabore um modelo, em nivel submicroscópico (e fazendo desenhos), para explicar as propriedades da resina de carimbo e da cola escolar observadas depois dos experimentos:

\section{Cola: [glue]}

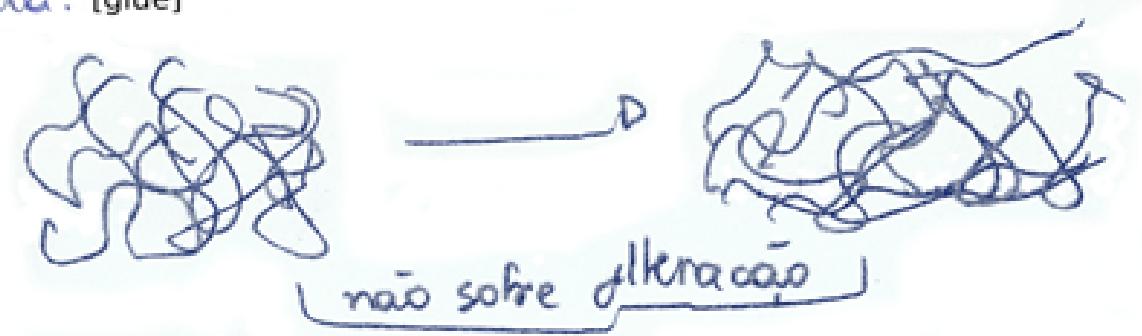

[does not change]

\section{Rusina de Carimbo: \\ [resin of stamp]}
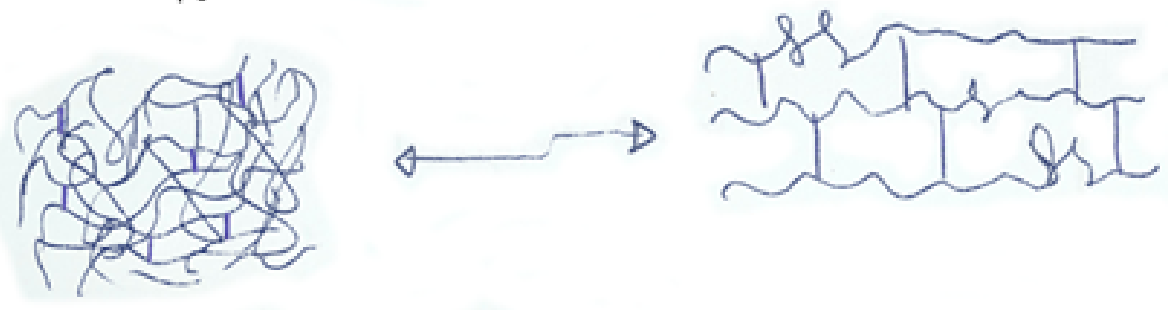

:Task 3: Based on your knowledge, draw a submicroscopic model to explain the properties of resin of stamp and school glue observed after the experiments:

Figure 8. Student's representation for glue and resin of stamp. 
Still in Table 2B, for resin of stamp (when $N=28$ ), 17 students were able to elaborate models (although incomplete) with characteristics of spaghetti-like representation shown in class and used in chemical textbooks. On the other hand, 11 students remained externalizing models similar to those elaborated in the previous teaching-learning sequence. In Figure 8, there is an example of complete representation for school glue and other to incomplete representation for resin of stamp, since in the latter only cross-linking formation process was not represented. The previous forms (alternative representations) can be seen in Figure 7.

The data showed, for glue and for resin of stamp, that occurrence of coherent or incomplete representations was greater than those representations that kept alternative characteristics, but the permanence of the latter affirms that the externalization of visual models through drawings is complex, thus it depends not only on high cognitive capacity but also depends on motor skills, according to Mnguni (2014), because "when drawing a diagram, the bodily-kinesthetic intelligence would play a role as it determines the way one moves his/her hand and fingers (Mnguni, 2014, p. 07)". Students can do both multiple and even contradictory drawings (Cheng \& Gilbert, 2009, p. 71).

At the end of this didactic sequence, a small questionnaire was applied. Table 3 shows that for school glue all respondents (22) correctly recognized the spaghetti-like representation to articulate it in their written responses. Since there were no transformations in this material, its level of difficulty can be considered low in relation to complexity of photopolymerization (it involves wavelength, it changes the material's physical behavior and introduces the formation of cross-linking).

On the other hand, 11 students had incomplete answers because they chose representations that already contained the cross-linking to represent the resin, since it was only formed after the UV light's action. This number reinforces the performance of previous incomplete representations when within the 17 incomplete responses, 13 occurrences were related to the absence or pre-existence of cross-linking concepts.

If the recognition of representations in the questionnaire was easier than its drawing (previous task), non-recognition of cross-linking decreased the frequency of correct answers (11 incomplete and 7 correct responses). This data can confirm that in learning of polymers, their own teaching can cause alternative conceptions (misconceptions) that hinder the internalization of their concepts. Similar evidence to the idea of "chain elongation" was also found:

The change in frequencies of misconceptions in this category [named: Polymer Chains Stretch Category] suggests that students were able to speak more technical about polymers following instruction, though there may have been some misconceptions created as a result. The additional misconceptions created may be substantive misconceptions, which could be difficult to repair (Kelly et al., 2010a, p. 13).

In summary, the results discussed point out advantages and disadvantages of the use of multiple representations in the teaching of polymers. On the one hand, this work has attempted to contribute to explore the role of spaghetti-like representations in polymer education through its function of Constructing Deeper Understanding and its Extension mode.

According to Ainsworth (2008), "extension can be considered as a way of transferring knowledge that a learner has from a known to an unknown representation, but without fundamentally reorganizing the nature of that knowledge (Ainsworth, 2008, p. 199)”. 
The fragments of macromolecules representations (stick-and-ball type) served to mobilize atomic-molecular concepts and properties (intermolecular forces) and then to be used (for an initial search for relations between them) with the new representation (more abstract) called spaghetti-like representation.

\section{Final Considerations}

A critical reflection on short course showed that demonstrative experiments articulated with visualization practice were valid and satisfactory within an initial exploratory study. While demonstrative experiments were able to motivate students and problematize basic concepts for polymers learning, the use of spaghetti-like representations requires further investigation.

This evaluation considered opportune to approach samples of both solid (amorphous) and colloidal (high viscosity liquid) polymers insofar as it suggests that creation of demonstrations about different viscosities (water, glue, resin) could help to teach the notions of average molecular mass of polymers and average size of the chains.

Another possibility suggested is the use of concrete objects to simulate the order of magnitude of polymer chains in relation to its monomer, from analogies using simple paper strips with relative sizes for each chemical species (e.g., water, polymer and its monomer). It could help students to understand the "inevitability" of van der Waals and hydrogen bonding interactions also occurring within the same polymer chain, leading to an entangled chain idea.

On the other hand, a limiting factor was the little time allocated for debate about externalized models by the students (drawings), because a sufficient time is needed to explore the similarities and differences between the elaborated models and scientific models. This could be overcome if this strategy was implemented in regular subjects of undergraduate course in Chemistry, and its activities were distributed throughout several classes.

Initiatives, as described in this article, explore introduction of visualization practices within thematic teaching-learning sequences to increase the quality of student learning and their interest in Polymer Chemistry, which are essential aspects in developing countries that need to build their own technologies and innovation.

\section{References}

ACD/ChemSketch (2010). (Version 12.01) [Computer software]. Toronto, Canada: ACD Labs.

Ainsworth, S. (2008). The educational value of multiple - representations when learning complex scientific concepts. In J. K. Gilbert, M. Reiner, M. Nakhleh (Eds.), Visualization: Theory and practice in science education (pp. 191-208). Dordrecht, Netherlands: Springer. doi:10.1007/978-1-4020-5267-5 9.

Amiri, B. (2016, January 11). How a CPU is made. [Video file] Retrieved from https://www.youtube. $\mathrm{com} / \mathrm{watch} ? \mathrm{v}=\mathrm{qm} 67 \mathrm{wbB} 5 \mathrm{GmI}$.

Arroio, A. (2012). Visualizations for natural science education. Journal of Baltic Science Education, 11(2), 112-114. Retrieved from http://www.scientiasocialis.lt/jbse/files/pdf/vol11/112-114. Arroio_Vol.11.2.pdf.

Atkins, P., \& Jones, L. (2012). Princípios de Química: questionando a vida moderna e o meio ambiente [Chemical principles: The quest for insight] (5th ed). Porto Alegre, Brazil: Bookman. 
Banerji, A., \& Tausch, M. W. (2011, June 21). Electroluminescense in organic light-emitting diodes. [Simulation]. Retrieved from http://www.chemiedidaktik.uni-wuppertal.de/flash/index.html.

Bardin, L. (1977) Análise de conteúdo [Content analysis] Lisbon, Portugal: Edições 70.

Cheng, M., \& Gilbert, J. K. (2009). Towards a better utilization of diagrams in research into the use of representative levels in chemical education. In: J. K. Gilbert, D. Treagust (Eds.), Multiple representations in chemical education (pp. 55-73). Dordrecht, Netherlands: Springer. doi:10.1007/978-1-4020-8872-8_4.

Douglas, E. P. (2008). Innovations in polymer education. Polymer Reviews, 48(4), 583-584. Retrieved from https://www.tandfonline.com/doi/abs/10.1080/15583720802445417. doi:10.1080/15583720802445417.

Eidenberger, L., Gollner, H., Altendorfer, F., \& Eidenberger, C. (2009). The latex motor. Science in School, 13, 34-38. Retrieved from https://www.scienceinschool.org/sites/default/files/ teaserPdf/issue13_latex.pdf.

Ford, W. T. (2017). Introducing the Journal of Chemical Education's “Special issue: Polymer concepts across the curriculum. Journal of Chemical Education, 94(11), 1595-1598. Retrieved from https://pubs.acs.org/doi/10.1021/acs.jchemed.7b00760. doi:10.1021/acs.jchemed.7b00760.

Galiazzi, M. do C., \& Gonçalves, F. P. (2004). A natureza pedagógica da experimentação: uma pesquisa na licenciatura em química [The pedagogical nature of experimental activities: research in a teaching credentials course in Chemistry]. Química Nova, 27 (2), 326-331. Retrieved from http://www.scielo.br/pdf/qn/v27n2/19283.pdf. doi:10.1590/S010040422004000200027.

Gilbert, J. K. (2005). Visualization: A metacognitive skill in science and science education. In: J. K. Gilbert (Eds.), Visualization in science education (pp. 09-27). Dordrecht, Netherlands: Springer. doi:10.1007/1-4020-3613-2_2.

Gilbert, J. K. (2008). Visualization: An emergent field of practice and enquiry in science education. In: J. K. Gilbert, M. Reiner, M. Nakhleh (Eds.), Visualization: Theory and practice in science education (pp. 03-24). Dordrecht, Netherlands: Springer. doi:10.1007/978-1-4020-52675 - 1 .

IUPAC. (1997). Compendium of Chemical Terminology (2nd ed). Oxford: Blackwell Scientific Publications. Retrieved from http://goldbook.iupac.org/pdf/goldbook.pdf.

Johnstone, A. H. (1991). Why is science difficult to learn? Things are seldom what they seem. Journal of Computer Assisted Learning, 7, 75-83. Retrieved from https://onlinelibrary. wiley.com/doi/pdf/10.1111/j.1365-2729.1991.tb00230.x doi: 10.1111/j.1365-2729.1991. tb00230.x.

Johnstone, A. H. (1993). The development of chemistry teaching: A changing response to changing demand. The Forum, 70 (9), 701-705. Retrieved from https://pubs.acs.org/doi/abs/10.1021/ ed070p701. doi:10.1021/ed070p701.

Kelly, J., Heinert, K., Triplett, J., Baker, D., \& Krause, S. (2010a, June). Uncovering and repairing atomic bonding misconceptions with multimodal assessments of student understanding in an introductory materials course. Proceedings of 2010 ASEE Annual Conference and Exposition. Louisville, Kentucky, US, 117th. Retrieved from https://peer.asee.org/ uncovering-and-repairing-atomic-bonding-misconceptions-with-multimodal-assessmentof-student-understanding-in-an-introductory-materials-course.pdf.

Kelly, J., Krause, S., \& Baker, D. (2010b, October). A pre-post topic assessment tool for uncovering misconceptions and assessing their repair and conceptual change. Proceedings of ASEE/ IEEE Frontiers in Education Conference. Washington, DC, US, 40th. Retrieved from https:// doi.org/10.1109/FIE.2010.5673206. doi:10.1109/FIE.2010.5673206.

Lemke, J. (1998). Multiplying meaning: Visual and verbal semiotics in scientific text. In J. R. Martin, \& R. Veel (Eds.), Reading science: Critical and functional perspectives on discourses of science (pp. 87-113). London, UK: Routledge.

Mayer, R. E. (2009). Multimedia learning (2nd ed). New York, US: Cambridge. doi:10.1017/ CBO9780511811678. 
Mayer, R. E. (2014). Cognitive theory of multimedia learning. In R. E. Mayer (Ed.), The Cambridge handbook of multimedia learning (pp. 43-71). New York, NY, US: Cambridge University Press. doi:10.1017/CBO9781139547369.005.

Méheut, M. (2005). Teaching-Learning sequences tools for learning and/or research. In: K. Boersma, M. Goedhart, O. de Jong, H. Eijkelhof (Eds.), Research and the Quality of Science Education (pp. 195-207). Dordrecht, Netherlands: Springer. doi:10.1007/1-4020-3673-6_16.

Mišeikis, V. (2010, January 29). Inside a SIM card [Photo]. Retrieved from https://www.flickr.com/ photos/v4idas/4314628422/.

Mnguni, L. E. (2014). The theoretical cognitive process of visualization for science education. SpringerPlus, 3(1), 1-9. Retrieved from https:/www.ncbi.nlm.nih.gov/pmc/articles/ PMC4000355/. doi:10.1186/2193-1801-3-184.

Nicholson, J. W. (2006). The Chemistry of Polymers (3rd ed). Cambridge: RSC. doi: $10.1039 / 9781847552655$

North, A. M. (2015). Teaching from polymer molecular structure to technological properties; requirements in developing countries. Macromolecular Symposia, 355(1), 32-38. https:// doi.org/10.1002/masy.201500037.

Oliveira, J. R. S. de. (2010). A perspectiva sócio-histórica de Vygotsky e suas relações com a prática da experimentação no ensino de Química [Vygotsky's sociohistorical perspective and its relationships with the practice of experimentation in Teaching Chemistry]. Alexandria: Revista de Educação em Ciência e Tecnologia, 3(3), 25-45. Retrieved from https:// periodicos.ufsc.br/index.php/alexandria/article/download/38134/29083.

Rapp, D. N. (2005). Mental models: Theoretical issues for visualizations in Science Education. In: J. K. Gilbert (Eds.), Visualization in science education (pp. 43-60). Dordrecht, Netherlands: Springer. doi:10.1007/1-4020-3613-2_4.

Santos, C. G. dos, Dias, M. L., \& Canevarolo, S. V. (2015). Polymer Education in Brazil: Present situation. Macromolecular Symposia, 355(1), 111-118. Retrieved from https://onlinelibrary. wiley.com/doi/epdf/10.1002/masy.201500071. doi:10.1002/masy.201500071.

Schofield, T. (2013, January 9). Samsung announces you flexible OLED displays at CES. [Video file] Retrieved from https://www.youtube.com/watch? $=$ =mLMWXBv5rY4.

Sizemore, J. (2016, June 11). Zoom into Plastic. [Video file] Retrieved from https://www.dailymotion. $\mathrm{com} / \mathrm{video} / \mathrm{x} 4 \mathrm{mukm}$.

Sweller, J. (2010). Cognitive load theory: Recent theoretical advances. In J. L. Plass, R. Moreno, \& R. Brünken (Eds.), Cognitive load theory. New York, NY, US: Cambridge University Press. doi:10.1017/CBO9780511844744.004.

Sweller, J., Ayres, P., \& Kalyuga, S. (2011). Cognitive Load Theory. New York: Springer. doi:10.1007/978-1-4419-8126-4.

Teraoka, I. (2002). Polymer solutions: An introduction to physical properties. New York, US: Wiley.

Tschopp, M. (2010, November 19). PE deformation. [Animated image] Retrieved from https://icme. hpc.msstate.edu/mediawiki/index.php/File:PE_deformation.gif.

Zandvoort, H. (1988). Macromolecules, dogmatism, and scientific change: the prehistory of polymer chemistry as testing ground for philosophy of science. Studies in History and Philosophy of Science Part A, 19(4), 489-515. doi:10.1016/0039-3681(88)90012-X. 
Received 19 December 2018; Accepted 18 May 2019

\section{Alceu Junior Paz da Silva}

MSc, Adjunct Professor, Institute of Exact Sciences, Fluminense Federal University, Rua Des. Ellis Hermydio Figueira, 783, CEP: 27213-145, Volta Redonda, Brazil.

E-mail: alceujunior@id.uff.br

Website: http://icex.sites.uff.br

\section{$\square \quad 0$ \\ Leopoldo José Alexandre}

BPharm, Teacher, Albert Einstein School, Rua Peru, CEP: 27197-000, Pinheiral, Brazil.

E-mail: leo.alexandre@gmail.com

Website: http://lattes.cnpq.br/3682351826074621

\section{$\square \quad 0$
 Agnaldo Arroio}

PhD., Professor, Faculty of Education, University of Sao Paulo, Sao Paulo, Brazil.

E-mail: agnaldoarroio@yahoo.com

Website: http://usp-br.academia.edu/AgnaldoArroio 